\title{
Producing of Microbial Oil by Mixed Culture of Microalgae and Oleaginous Yeast Using Sugarcane Molasses as Carbon Substrate
}

\author{
Thidarat Papone, Supaporn Kookkhunthod, Mutiyaporn Paungbut, and Ratanaporn Leesing
}

\begin{abstract}
The oleaginous microorganisms involving yeasts and microalgae have the potential to generate significant quantities of biomass and oil suitable for conversion to biodiesel. Compared to microbial oil production, little work has been performed for mixed culture of microalgae and yeast. In this work, microbial oil production from mono and mixed cultures of microalgae Chlorella sp. KKU-S2 and yeast Toluraspora maleeae Y30, Toluraspora globosa YU5/2 under mixotrophic cultivation using sugarcane molasses as carbon substrate was demonstrated. In monoculture, a biomass of $5.23 \mathrm{~g} / \mathrm{L}$ with lipid yield of $0.31 \mathrm{~g} / \mathrm{L}, 9.43 \mathrm{~g} / \mathrm{L}$ of biomass with lipid yield of $0.20 \mathrm{~g} / \mathrm{L}$, $3.3 \mathrm{~g} / \mathrm{L}$ with lipid yield of $0.12 \mathrm{~g} / \mathrm{L}$ was obtained from $T$. maleeae Y30, T. globosa YU5/2 and Chlorella sp. KKU-S2, respectively. In mixed culture of microalgae Chlorella sp. KKU-S2 and $T$. maleeae Y30, a biomass of $5.47 \mathrm{~g} / \mathrm{L}$ and lipid yield of $0.25 \mathrm{~g} / \mathrm{L}$ were obtained. A biomass of $6.90 \mathrm{~g} / \mathrm{L}$ with lipid yield of $0.33 \mathrm{~g} / \mathrm{L}$ was obtained for a mixed culture of $T$. globosa YU5/2 with Chlorella sp. KKU-S2. Maximum process product yield $\left(Y_{P / S}\right)$ of $0.03 \mathrm{~g} / \mathrm{L}$ and maximum volumetric lipid production rate $\left(Q_{P}\right)$ of 0.041 were obtained in mixed culture of $T$. globosa YU5/2 with Chlorella sp. KKU-S2. The results obtained from this study shows that mixed culture of the oleaginous yeast with microalgae is a desirable cultivation process for enhance of microbial oil production.
\end{abstract}

Index Terms-Microbial lipid, microalgae, oleaginous yeast, mixed culture.

\section{INTRODUCTION}

Microbial oil produced from many oleaginous microorganisms involving yeasts, moulds, and microalgae are known as promising candidates for biodiesel production because of their advantages of higher biomass production and faster growth compared to other energy crops and their fatty acid compositions are similar to vegetable oils [1], [2]. Microalgae consume carbon dioxide $\left(\mathrm{CO}_{2}\right)$ which can reduces $\mathrm{CO}_{2}$, greenhouse gas as an environmental pollution,

Manuscript received September 25, 2014; revised June 20, 2015. This work was financially supported by the Higher Education Research Promotion and National Research University Project of Thailand, Office of the Higher Education Commission, through the Biofuel Cluster of Khon Kaen University and Human Resource Development in Science Project, Office of the Higher Education Commission through Science Achievement Scholarship of Thailand (SAST) and Khon Kaen University (KKU) Research Fund, fiscal years 2013-2014.

Thidarat Papone, Supaporn Kookkhunthod, and Mutiyaporn Paungbut are with the Graduate School of Khon Kaen University, Khon Kaen 40002, Thailand (e-mail: thidarat.p@kkumail.com, mutiyapornp@kkumail.com, Supaporn.kookkhunthod.mam@gmail.com).

Ratanaporn Leesing is with the Department of Microbiology, Faculty of Science, Khon Kaen University, he is also with the Alternative Energy Research and Development (AERD) and Fermentation Research Center for Value Added Agricultural Products (FerVAAP), Khon Kaen University, Khon Kaen, 40002, Thailand (e-mail: ratlee@kku.ac.th). therefore, biodiesel production from microalgae lipids is increasingly regarded as a more sustainable and feasible alternative to conventional biodiesel feedstock derived from terrestrial bio-energy crops [3], [4]. Microalgae can trap light energy as the energy source and assimilate $\mathrm{CO}_{2}$ as the carbon source and organic substrates can also be utilized as the carbon and energy sources by many microalgae [5].

Microalgae may assume many types of metabolisms, such as photoautotrophic, heterotrophic, photoheterotrophic and mixotrophic growths [6]. Mixotrophic microalgae growths can simultaneously drive photoautotrophic and heterotrophic to utilize both $\mathrm{CO}_{2}$ and organic carbon substrates, they assimilate organic compounds and $\mathrm{CO}_{2}$ as a carbon source, and the $\mathrm{CO}_{2}$ released by microalgae via respiration will be trapped and reused under phototrophic growth [7].

Lipid content of some microalgae such as Scenedesmus sp., Chlorella sp., Neochloris oleoabundans, Spirulina maxima, Euglena gracilis can achieve from $10 \%$ to $50 \%$ of total cell dry weight [6], [8], revealing the significant potential of biodiesel production. The cellular lipid content in microalgae reaches 75\% in Botryococcus braunii, but is associated with a low productivity of biomass [1], [9]. Microalgae Chlorella sp. are widely available strains in the commercial applications as they presented high potentials as biodiesel producers due to their high growth rate, and their high lipid contents [2], [8]. However, the isolated microalgae Chlorella sp. KKU-S2 can grow under photoautotrophic, heterotrophic and mixotrophic conditions and their fatty acid components were palmitic acid, stearic acid, oleic acid and linoleic acid [10].

Oleaginous yeasts are capable of accumulating large amounts of cellular lipids and it also has a high growth rate and some oleaginous yeast strains such as Rhodosporidium sp., Rhodotorula sp. can accumulate cellular lipids to level exceeding $70 \%$ of their biomass [11]. The isolated yeast Torulaspora maleeae Y30 and Torulaspora globosa YU5/2 can accumulate high lipid yield and their fatty acids profiles were palmitic acid, stearic acid, and oleic acid that are comparable to vegetable oils [12], [13].

Mixed cultures are two or more preselected species of microorganism are synchronously cultivated within the same medium [14]. In the mixed culture of yeast and microalgae, under mixotrophic culture, microalgae could act as an oxygen generator for the yeast while the yeast provided $\mathrm{CO}_{2}$ to microalgae and both carried out production of microbial oils [3], [4].

Currently, the cost of biodiesel produced from microbial oil is much higher than that of diesel derived from petroleum due to the lower culture process efficiency and higher cost of feedstock production is mainly contributed by microbial 
cultivation including biomass, lipid accumulation and extraction is essential step as feedstock takes up to $70 \%$ of the overall cost [15], [16]. Due to high production costs of microbial oil, the use of inexpensive carbon substrate containing sugar such as sugarcane molasses to cultivate the oleaginous microorganisms could reduce these costs. This study have proved an approach for the production of microbial oils by mixed culture of isolated microalgae and yeasts on sugarcane molasses, suggesting that they have potential of converting sugarcane molasses, a by-product of refining sugar factory to microbial oils under mixotrophic cultivation, and compare them with those under monoculture conditions.

\section{MATERIALS AND METHODS}

\section{A. Carbon Substrate, Microorganisms, Culture Conditions}

The carbon substrate used in this study was sugarcane molasses collected from a local market in Khon Kaen province, Thailand. The pre-treated sugarcane molasses was mixed with sulfuric acid for final concentration of $1 \%(\mathrm{v} / \mathrm{v})$. The mixture was treated in water baht at $100^{\circ} \mathrm{C}$ for $20 \mathrm{~min}$. After cooling, the liquid fraction as sugarcane molasses hydrolysate $(\mathrm{SMH})$ was separated by centrifugation to remove insoluble particles. Then, reducing sugar was analyzed by DNS method and adjusted the reducing sugar to obtain desirable concentration for used as the carbon source.

The microalgae Chlorella $\mathrm{sp}$. KKU-S2 was isolated from freshwater taken from pond in the area of Khon Kaen province, Thailand. The seed culture was pre-cultivated onto Bristol's medium supplemented with $20 \mathrm{~g} / \mathrm{L}$ glucose and sugarcane molasses hydrolysate as carbon substrate at room temperature in an incubator shaker at a shaking speed of 150 rpm for 3 days under continuous illuminated from overhead by $80 \mathrm{~W}$ cool-white fluorescent lamps. The Bristol's medium contained the following components $(\mathrm{mg} / \mathrm{L}): \mathrm{NaNO}_{3} 250$, $\mathrm{K}_{2} \mathrm{HPO}_{4} 75, \mathrm{KH}_{2} \mathrm{PO}_{4} 175, \mathrm{CaCl}_{2} 25, \mathrm{NaCl} 25, \mathrm{MgSO}_{4} \cdot 7 \mathrm{H}_{2} \mathrm{O}$ $75, \mathrm{FeCl}_{2} 0.3, \mathrm{MnSO}_{4} \cdot 2 \mathrm{H}_{2} \mathrm{O} 0.3, \mathrm{ZnSO}_{4} \cdot 7 \mathrm{H}_{2} \mathrm{O} 0.2, \mathrm{H}_{3} \mathrm{BO}_{3}$ $0.2, \mathrm{CuSO}_{4} \cdot 5 \mathrm{H}_{2} \mathrm{O} 0.06$, and $\mathrm{pH}$ will be adjusted to 6.0 before sterilization.

The oleaginous yeasts Torulaspora maleeae Y30 and Torulaspora globosa YU5/2 used in this study were isolated from soil samples taken from forest in the area of Chaiyapoom and Udonthani provinces northeastern of Thailand. The seed cultures were cultivated onto Lipid accumulation (LA) medium supplemented with 20g/L glucose and sugarcane molasses hydrolysate as carbon substrate at room temperature in an incubator shaker at 150 rpm for 1 day. The LA medium was consisted of $(\mathrm{g} / \mathrm{L})$ : $\left(\mathrm{NH}_{4}\right) 2 \mathrm{SO}_{4} 0.1, \mathrm{KH}_{2} \mathrm{PO}_{4} \quad 0.4, \mathrm{MgSO}_{4} \cdot 7 \mathrm{H}_{2} \mathrm{O} \quad 1.5, \mathrm{ZnSO}_{4}$ $0.0044, \mathrm{CaCl}_{2} 0.0025, \mathrm{MnCl}_{2} 0.0005, \mathrm{CuSO}_{4} 0.0003$ and yeast extract 0.75 and $\mathrm{pH}$ is adjusted to 5.5 before sterilization.

\section{B. Microbial Oil Production by Mono and Mixed Cultures}

Batch cultivations were performed in $500 \mathrm{~mL}$ Erlenmeyer flasks, each containing $300 \mathrm{~mL}$ of medium contained $20 \mathrm{~g} / \mathrm{L}$ sugarcane molasses hydrolysate as carbon substrate. The experiments were performed in form of monoculture of each T. maleeae Y30, T. globosa YU5/2, Chlorella sp. KKU-S2 and mixed culture of Chlorella sp. KKU-S2 with T. maleeae Y30, Chlorella sp. KKU-S2 with T. globosa YU5/2. The seed cultures were $5 \%$ yeast and $5 \%$ microalgae $(\mathrm{v} / \mathrm{v})$ for mixed culture and $10 \%(\mathrm{v} / \mathrm{v})$ of each strain for monoculture, cultivated at room temperature in an incubator rotary shaker at a shaking speed of $150 \mathrm{rpm}$ under continuous illumination by using $80 \mathrm{~W}$ cool-white fluorescent lamps for mixotrophic growth of microalgae and mixed culture of yeast and microalgae.

\section{Analytical Methods}

Duplicate samples were analyzed for cell dry weight, harvested biomass was washed twice with distilled water and then dried at $90^{\circ} \mathrm{C}$ to constant weight. The biomass was measured gravimetrically. The total lipids were determined by the modified method of Kwon and Rhee [17]. Lipid content was expressed as gram lipid per gram dry biomass, while residual glucose concentration from supernatant was analyzed according to DNS method [18].

Volumetric lipid production rate $\left(Q_{P}\right)$ was determined from a plot between lipids $(\mathrm{g} / \mathrm{L})$ and fermentation time, process product yield $\left(Y_{P / S}\right)$ was determined from $\mathrm{d} P / \mathrm{d} S$, and specific product yield $\left(Y_{P / X}\right)$ was determined using relationship $\mathrm{d} P / \mathrm{d} X$, while volumetric rate of substrate consumption $\left(Q_{S}\right)$ was determined from a plot between substrate $(\mathrm{g} / \mathrm{L})$ present in the fermentation medium and fermentation time.

Volumetric cell mass production rate $\left(Q_{X}\right)$ was determined from a plot of dry cells $(\mathrm{g} / \mathrm{L})$ versus time of fermentation $(\mathrm{d})$. The specific growth rate $(\mu)$ is the slope determined by plotting the natural log of biomass versus time for each substrate concentration during the initial phase of exponential growth before the substrate concentration decreases significantly while specific rate of lipid production $(q P)$ was a multiple of $\mu$ and $Y_{P / X}$.

\section{Abbreviations}

$P$ : Lipid concentration (g/L), $Q_{P}$ : Volumetric lipid production rate $(\mathrm{g} / \mathrm{L} / \mathrm{d}), \quad Q s$ : Volumetric substrate consumption rate (g substrate/L/d), $Q_{X}$ : Volumetric biomass production rate $(\mathrm{g}$ cells/L/d), $q P$ : Specific rate of lipid production (g lipid /g cells/d), qs: Specific rate of substrate consumption (g substrate/g cells/ $\mathrm{d}), \quad S$ : Substrate concentration $(\mathrm{g} / \mathrm{L}), X$ : Cell mass concentration $(\mathrm{g} / \mathrm{L}), Y_{P / S}$ : Process product yield (g lipid/g substrate), YP/X: Specific yield of lipid (g lipid/g cells), YX/S: Cell yield coefficient ( $\mathrm{g}$ cells/g substrate), $\mu$ : Specific growth rate coefficient (1/d).

\section{RESULTS AND DISCUSSION}

Comparison of microbial cultivations by monoculture and mixed cultures of oleaginous yeast $T$. maleeae Y30, $T$. globosa YU5/2, microalgae Chlorella sp. KKU-S2 using sugarcane molasses as carbon substrate by batch cultivations were investigated. Reducing sugar, $\mathrm{pH}$ of medium, biomass and lipid production of monoculture and mixed cultures are presented in Fig. 1 and Table I. SMH referred to reducing sugar, Fig. 1(a) apparent that oleaginous yeast can use SMH faster than microalgae. It is presented that reducing sugar was used mainly for cell growth at the beginning of the cultivation time. 

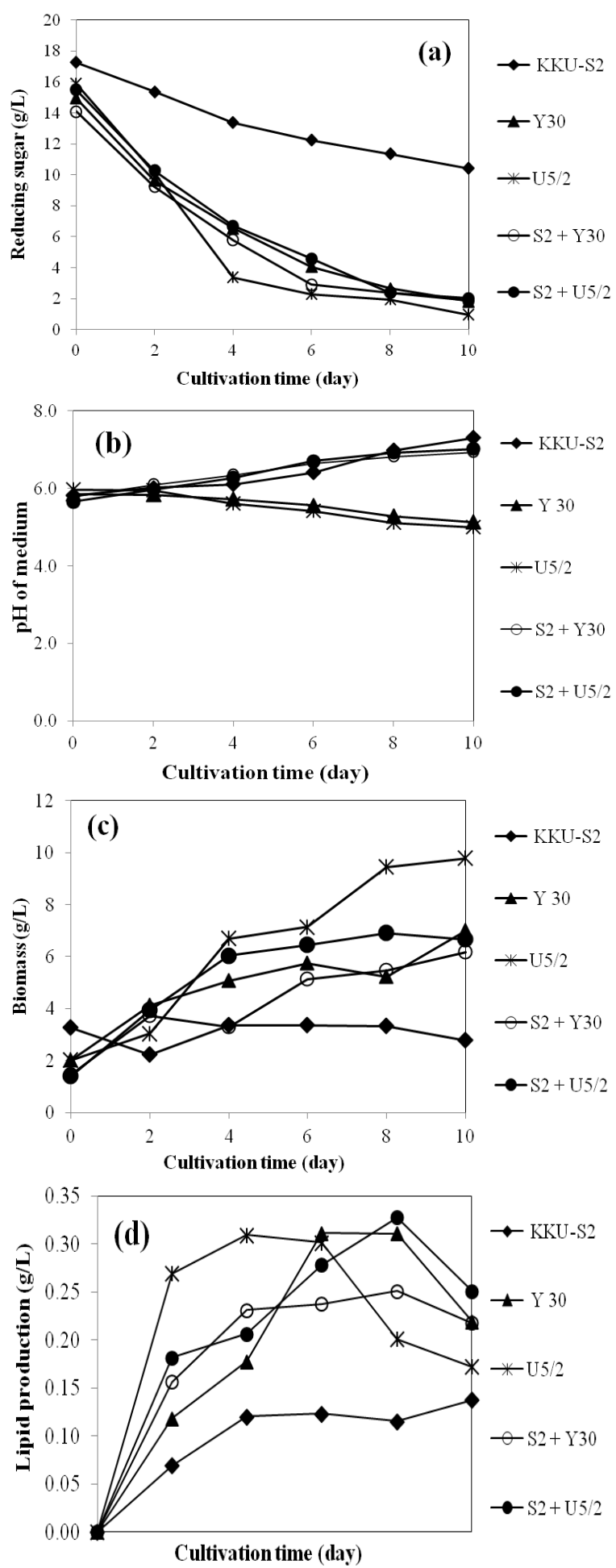

Fig. 1. Residue sugar (a), $\mathrm{pH}$ of medium (b), biomass concentration (c) and lipid production (d) during cultivation of monoculture of T. maleeae Y30 (Y30), T. globosa YU5/2 (U5/2), Chlorella sp. KKU-S2 (KKU-S2) and mixed cultures of Chlorella sp. KKU-S2 with T. maleeae Y30 (S2+Y30), Chlorella sp. KKU-S2 with T. globosa YU5/2 (S2+U5/2) using SMH as carbon substrate for 10 days.

After cultivation of microalgae, $\mathrm{pH}$ of medium increased from 5.5 to 7.0 for mixed culture and from 5.8 up to 7.3 for monoculture. When $\mathrm{CO}_{2}$ dissolves in water at neutral $\mathrm{pH}$, bicarbonate $\left(\mathrm{HCO}_{3}-\right)$ formed. During photosynthesis activity by microalgae, $\mathrm{HCO}_{3}$ - is converted to $\mathrm{CO}_{2}$ and hydroxide ion $(\mathrm{OH}-)$. Therefore, when $\mathrm{CO}_{2}$ is consumed by microalgae, the $\mathrm{OH}$ - is formed, and the $\mathrm{pH}$ becomes more alkaline [19].

In monoculture, T. maleeae Y30, T. globosa YU5/2 grew faster than that microalgae Chlorella sp. KKU-S2. The biomass of $5.23 \mathrm{~g} / \mathrm{L}$ with specific growth rate of $0.206(1 / \mathrm{d})$ and lipid production of $0.31 \mathrm{~g} / \mathrm{L}$ were obtained from $T$. maleeae $\mathrm{Y} 30$, while $9.43 \mathrm{~g} / \mathrm{L}$ of biomass with specific growth rate of $0.28(1 / \mathrm{d})$ and lipid production of $0.2 \mathrm{~g} / \mathrm{L}$ were obtained for monoculture of $T$. globosa YU5/2. A biomass of $3.33 \mathrm{~g} / \mathrm{L}$ with specific growth rate of $0.15(1 / \mathrm{d})$ and lipid production of $0.12 \mathrm{~g} / \mathrm{L}$ were found from Chlorella sp. KKU-S2.

TABLE I: FERMENTATION KinETIC PARAMETERS OF BATCH MIXOTROPHIC CULTIVATION OF THE MONOCULTURE AND MiXed Culture OF T. MALEEAE Y30, T. GLOBOSA YU5/2 AND MICROALGAE CHLORELLA SP. KKU-S2 ON THE Culture Medium Using Sugarcane Molasses as Carbon Substrate AT ROOM TEMPERATURE, 150 RPM UNDER CONTINUOUS ILLUMINATION BY USING 80W COOL-WHITE FLUORESCENT LAMPS FOR 10 DAYS

\begin{tabular}{|c|c|c|c|c|c|}
\hline \multirow{2}{*}{$\begin{array}{l}\text { Kinetic } \\
\text { parameters }\end{array}$} & \multicolumn{5}{|c|}{ Microbial Cultures } \\
\hline & KKU-S2 ${ }^{1}$ & $\mathbf{Y 3 0}^{2}$ & $\mathrm{U} 5 / 2^{3}$ & $\underset{\mathrm{Y}^{2} 0^{4}}{\text { KKU-S2 }}+$ & $\begin{array}{l}\text { KKU-S2 } \\
+ \text { U5/2 }\end{array}$ \\
\hline$X$ & 3.33 & 5.23 & 9.43 & 5.47 & 6.90 \\
\hline$P$ & 0.12 & 0.31 & 0.20 & 0.25 & 0.33 \\
\hline$Y_{X / S}$ & 0.56 & 0.43 & 0.68 & 0.47 & 0.53 \\
\hline$Y_{P / S}$ & 0.02 & 0.03 & 0.01 & 0.02 & 0.03 \\
\hline$Y_{P / X}$ & 0.03 & 0.06 & 0.02 & 0.05 & 0.05 \\
\hline$Q_{s}$ & 0.74 & 1.54 & 1.74 & 1.46 & 1.64 \\
\hline$Q_{X}$ & 0.42 & 0.65 & 1.18 & 0.68 & 0.86 \\
\hline$Q_{P}$ & 0.014 & 0.039 & 0.025 & 0.031 & 0.041 \\
\hline$q_{S}$ & 1.77 & 2.35 & 1.48 & 2.14 & 1.90 \\
\hline$q_{P}$ & 0.03 & 0.06 & 0.02 & 0.05 & 0.05 \\
\hline$\mu$ & 0.15 & 0.21 & 0.28 & 0.21 & 0.24 \\
\hline
\end{tabular}

${ }^{1}$ Monoculture of Chlorella sp. KKU-S2,

${ }^{2}$ Monoculture of T. maleeae $\mathrm{Y} 30$,

${ }^{3}$ Monoculture of T. globosa YU5/2,

${ }^{4}$ Mixed culture of Chlorella sp. KKU-S2 with T. maleeae Y30,

${ }^{5}$ Mixed culture of Chlorella sp. KKU-S2 with T. globosa YU5/2

The obtained result in mixed culture showed that mixed culture of microalgae Chlorella sp. KKU-S2 and T. globosa YU5/2 grew faster than that of Chlorella sp. KKU-S2 and $T$. maleeae $\mathrm{Y} 30$. A high biomass of $6.90 \mathrm{~g} / \mathrm{L}$ with volumetric biomass production rate of $0.86 \mathrm{~g} / \mathrm{L} / \mathrm{d}$ and specific growth rate of $0.24(1 / \mathrm{d})$ and lipid production of $0.33 \mathrm{~g} / \mathrm{L}$ were obtained from mixed culture of Chlorella sp. KKU-S2 and T. globosa YU5/2. While, a biomass of $6.17 \mathrm{~g} / \mathrm{L}$ with volumetric biomass production rate of $0.68 \mathrm{~g} / \mathrm{L} / \mathrm{d}$ and specific growth rate of 0.21 $(1 / \mathrm{d})$, lipid production of $0.25 \mathrm{~g} / \mathrm{L}$ were found for a mixed culture of Chlorella sp. KKU-S2 with T. maleeae Y30.

In case of monoculture of $T$. globosa YU5/2, high concentration of biomass was found. It is possible to describe that amount of initial seed culture can affected on cell growth. Due to yeasts grew faster than that of microalgae, the seed culture of monoculture of yeast $(10 \%, \mathrm{v} / \mathrm{v})$ that have large amount than yeast in seed culture of the mixed culture which have $5 \%$ of yeast and $5 \%$ microalgae of seed culture. Hence, monoculture of yeast $T$. globosa YU5/2 obtained a higher biomass when compared to mixed culture.

Maximum cell yield coefficient $(Y \mathrm{x} / \mathrm{s}, \mathrm{g} / \mathrm{L})$ was found of 0.68 in monoculture of $T$. globosa YU5/2 but low level of both specific yield of lipid (YPXX, g lipid/g cells) of 0.02 and volumetric lipid production rate $\left(Q_{P}, \mathrm{~g} / \mathrm{L} / \mathrm{d}\right)$ of 0.025 were observed. Maximum lipid production $(P)$ of $0.33 \mathrm{~g} / \mathrm{L}$, lipid 
yield of $0.03 \mathrm{~g} / \mathrm{L}$ and maximum volumetric lipid production rate $\left(Q_{P}\right)$ of 0.041 were obtained in mixed culture of $T$. globosa YU5/2 with Chlorella sp. KKU-S2. In the mixed culture, the microalgae may role as an $\mathrm{O}_{2}$ producer and the yeast produced $\mathrm{CO}_{2}$ that could be used by the microalgae, the metabolic reactions of both $\mathrm{CO}_{2}$ release and uptake were combined and complementary [20].

The data obtained in the experimental results agreed with the data reported by Cheirsilp et al., (2011), the highest biomass of $4.63 \mathrm{~g} / \mathrm{L}$ and lipid production of $2.88 \mathrm{~g} / \mathrm{L}$ were obtained after 5 days of cultivation when using molasses as carbon substrate from the mixed culture of oleaginous yeast Rhodotorula glutinis and microalga Chlorella vulgaris [21].

\section{CONCLUSIONS}

In conclusion, this mixed culture of the oleaginous yeast $T$. globosa YU5/2 and microalgae Chlorella sp. KKU-S2 strategy led to significant improvements in growth, biomass concentration and lipid production. The experimental obtained results presented that microbial oil production from mixed culture can be performed with low cost production process to biodiesel feedstock preparing using a by-products sugarcane molasses as carbon substrate under mixotrophic cultivation.

In further works, factor affecting on growth and lipid production such as initial of seed culture ratio of microalgae and yeast, concentration of sugarcane molasses, nitrogen source, cultivation type such as fed-batch fermentation, even up-scaling of microbial oil production will be considered through mixed culture of microalgae with yeast and completed with the production of biodiesel from microbial oil by indirect and direct transesterification.

\section{REFERENCES}

[1] G. H. Huang, F. Chen, D. Wei, X. W. Zhang, and G. Chen, "Biodiesel production by microalgal biotechnology," Appl Energ, vol. 87, pp. $38-46,2010$

[2] X. Meng, J. Yang, X. Xu, L. Zhang, Q. Nie, and M. Xian, "Biodiesel production from oleaginous microorganisms," Renewable Energy, vol. 34, pp. 1-5, 2009.

[3] T. M. Mata, A. A. Martins, and N. S. Caetano, "Microalgae for biodiesel production and other applications: A review," Renew. Sust. Energ. Rev, vol. 14, pp. 217-232, 2010.

[4] T. T. Y. Doan, B. Sivaloganathan, and J. P. Obbard, "Screening of marine microalgae for biodiesel feedstock," Biomass and Bioenergy, vol. 35, pp. 534-2544, 2011.

[5] M. R. Droop, "Heterotrophy of carbon," in Algal Physiology and Biochemistry, W. D. P. Stewart, Ed. University of California Press, California, 1974, pp. 530-560.

[6] L. Brennan and P. Owende, "Biofuels from microalgae-a-review of technologies for production, processing, and extractions of biofuels and co-products," Renew Energ Rev, vol. 14, pp. 557-577, 2010.

[7] T. Heredia-Arroyo, W. Wei, R. Ruan, and B. Hu, "Mixotrophic cultivation of Chlorella vulgaris and its potential application for the oil accumulation from non-sugar materials," Biomass Bioenergy, vol. 35 , pp. 2245-2253, 2011.

[8] Z. Y. Liu, G. C. Wang, and B. C. Zhou, "Effect of iron growth and lipid accumulation in Chlorella vulgaris," Bioresour Technol, vol. 99, pp. 4717-22, 2007.

[9] X. Miao and Q. Wu, "Biodiesel production from heterotrophic microalgal oil," Bioresour Technol, vol. 97, pp. 841-6, 2006.

[10] R. Leesing and N. Nontaso, "Microalgal oil production by green microalgae under heterotrophic cultivation," KKU Res J, vol. 9, pp. 787-793, 2010.

[11] O. Tehlivets, K. Scheuringer, and S. D. Kohlwein, "Fatty acid synthesis and elongation in yeast," Biochimica et Biophysica Acta, vol. 1771, pp. 255-270, 2007.
[12] R. Leesing and P. Karraphan, "Kinetic growth of the isolated oleaginous yeast for lipid production," African J Biotechnol, vol. 63, pp. 13867-13877, 2011.

[13] R. Leesing and R. Baojungharn, "Microbial Oil Production by Isolated Oleaginous Yeast Torulaspora globosa YU5/2," in Proc. World Academy of Science, Engineering and Technology, vol. 76, pp. 1088-1092, 2011.

[14] A. M. O'Reilly and J. A Scott, "Defined coimmobilization of mixed microorganism cultures," Enzyme Microb. Technol, vol. 17, pp. 636-646, 1995.

[15] B. Singh, A. Guldhe, I. Rawat, and F. Bux, "Towards a sustainable approach for development of biodiesel from plant and microalgae," Renew. Sustain. Energy Rev, vol. 29, pp. 216-245, 2014.

[16] D. Pimentel and T. W. Patzek, "Ethanol production using corn, switch grass, and wood; diesel production using soybean and sunflower," Natural Resources Research, vol. 14, pp. 65-76, 2005.

[17] D. Y. Kwon and J. S. Rhee, "A Simple and rapid colorimetric method for determination of free fatty acids for lipase assay," J. Am. Oil. Chem. Soc., vol. 63, pp. 89-92, 1986.

[18] G. L. Miller, "Use of dinitrosalicylic acid reagent for determination of reducing sugar," Anal Chem, vol. 31, pp. 426-432, 1959.

[19] A. Richmond, Microalgal Mass Culture, CRC Press, 1986.

[20] F. Xue, J. Miao, X. Zhang, and T. Tan, "A new strategy for lipids production by mix cultivation of Spirulina platensis and Rhodotorula glutinis," Appl Biochem Biotechnol, vol. 160, pp. 498-503, 2010.

[21] B. Cheirsilp, W. Suwannarat, and R. Niyomdecha, "Mixed culture of oleaginous yeast Rhodotorula glutinis and microalga Chlorella vulgaris for lipid production from industrial wastes and its use as biodiesel feedstock," New Biotechnology, vol. 28, no. 4, pp. 362-368, 2011.

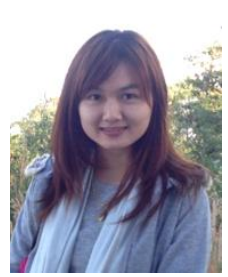

Thidarat Papone obtained her bachelor degree of science in biology from Mahasarakham University, Mahasarakham, Thailand. Currently she is a Ph.D. student at the Department of Microbiology, Faculty of Science, Khon Kaen University Thailand. Her major $\mathrm{Ph} . \mathrm{D}$. research study areas include microbial oil production from microalgae and oleaginous yeasts and microbial oil-based biodiesel production.

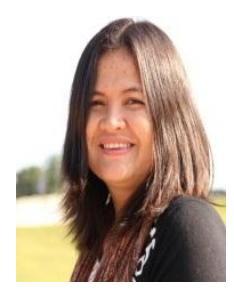

Supaporn Kookkhunthod got her bachelor of science degree in microbiology from Khon Kaen University, Khon Kaen, Thailand. Currently she is a master degree student at the Department of Microbiology, Faculty of Science, Khon Kaen University, Khon Kaen, Thailand. Her master research study area is focusing on cultivation of microalgae for biomass and lipid production and microalgae-based biodiesel production.

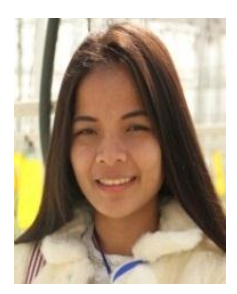

Mutiyaporn Paungbut obtained her bachelor of science degree in biology from Mahasarakham University, Mahasarakham, Thailand. She received her mater degree of science in microbiology from Khon Kaen University, Thailand. She is now a Ph.D. student at the Department of Microbiology, Faculty of Science, Khon Kaen University Thailand. Her research interest for $\mathrm{Ph} . \mathrm{D}$. is cultivation of mixed culture of microalgae and yeast and conversion of microbial biomass to biodiesel fuel.

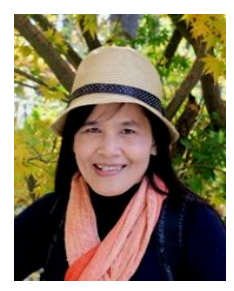

Ratanaporn Leesing is an assistant professor in the Department of Microbiology, Faculty of Science, Khon Kaen University, Khon Kaen, Thailand. She obtained the B.Sc. degree in biology-microbiology from Khon Kaen University, Khon Kaen, Thailand. She received the M.Sc. degree in biotechnology from King Mongkut's University of Technology Thonburi, Bangkok, Thailand and graduated with a Ph.D. degree in food sciences from the University of Montpellier II, Montpellier, France. Her recent research interest and teaching activities are in the field of bio-resources, bio-energy and fermentation technology. 